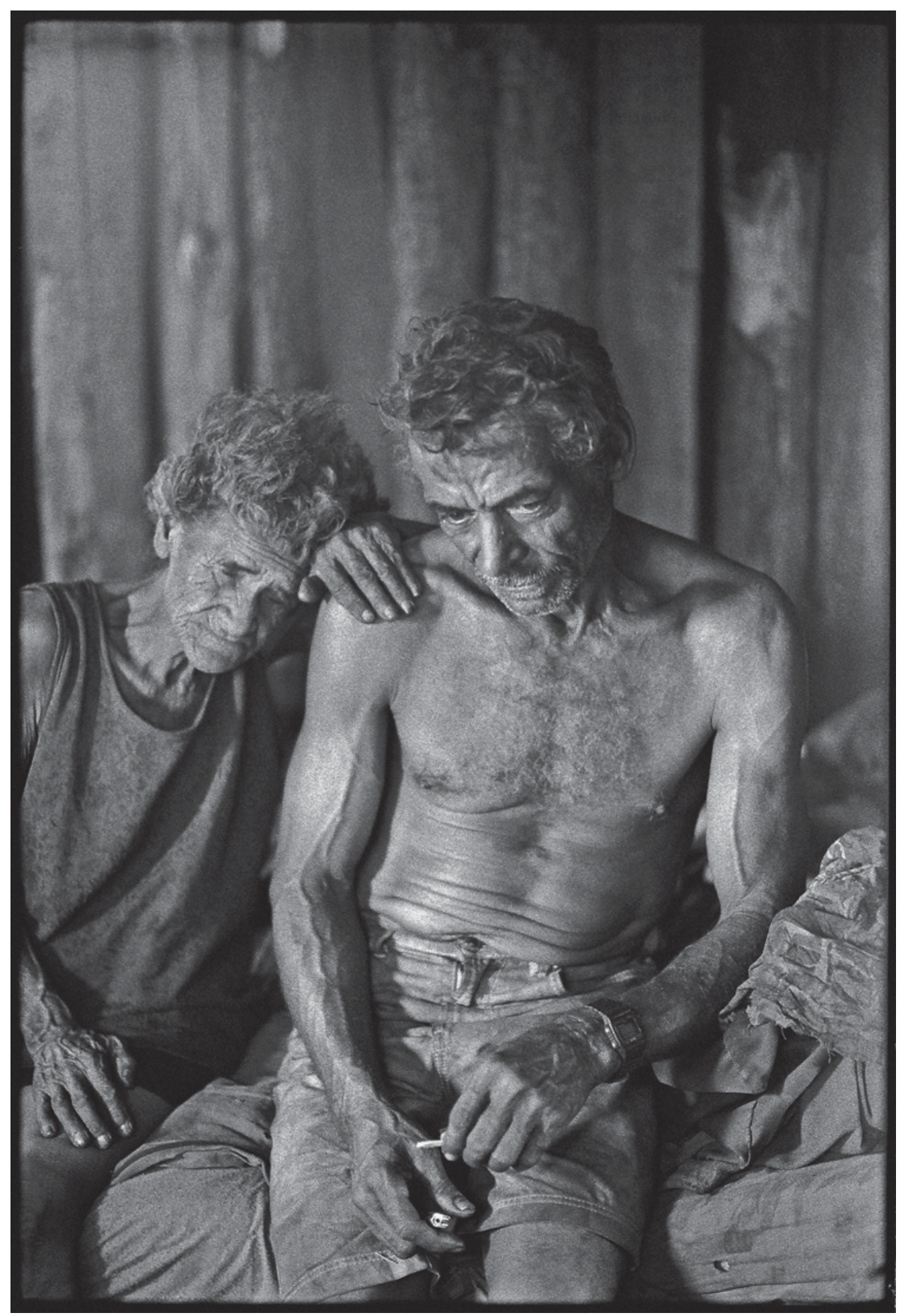

Fotografias: João Roberto Ripper 


\title{
História de uma fratura: a desagregação social como fundamento da formação sócio-histórica brasileira
} History of a fracture: social disaggregation as the foundation
of the Brazilian socio-historical formation

Mariela Natalia Becher*

Resumo - Este artigo pretende discutir sobre as ideias de desagregação social como parte do nascimento do Brasil e da colônia latinoamericana, baseadas na tese central de Caio Prado Jr., observando que a colonização foi uma "grande empresa comercial" que nunca teve como objetivo povoar estes territórios. Fratura social que nos sucessivos momentos da história do Brasil adquire diferentes particularidades, mas nunca deixa de existir e de se aprofundar. Frente à crise estrutural do capital, esta desagregação se aprofunda e se reproduz de uma maneira exponencial e com novas características.

Palavras-chave: fratura social; nexo moral; acumulação primitiva; arcaico e moderno; crise estrutural.

\begin{abstract}
This article aims to discuss the ideas of social disintegration as part of the birth of Brazil and the Latin American colony. It is based on the central thesis of Caio Prado Jr. who analyzed colonization as a "big trade company" that never aimed to populate these territories. A social fracture that at successive moments of Brazil's history acquires different characteristics, but never ceases to exist and deepen. In front of the capital's structural crisis, this breakdown deepens and reproduces in an exponential manner and with new features.
\end{abstract}

Keywords: social fracture; moral nexus; primitive accumulation; archaic and modern; structural crisis.

\footnotetext{
* Doutora em Serviço Social. Professora adjunta da Faculdade de Serviço Social da Universidade do Estado do Rio de Janeiro. Membro do Grupo de Estudo e Pesquisa sobre Seguridade Social (GOPSS). Coordenadora do projeto de extensão "Estado e Fundo Público". Correspondência: Rua São Francisco Xavier, 524/sl. 8029/B - bloco E, 8º andar. CEP: 20550-900. E-mail: <marielabecher@gmail.com>
} 


\section{Introdução}

Das leituras propostas por Caio Prado Jr., sobre a formação social brasileira, surgiram ao menos dois caminhos de interpretação: há, por um lado, análises centradas em entender a regressão do progresso e as consequências do projeto civilizatório para a América Latina. Este projeto trouxe consigo a proposta de modernização tardia, aprofundando um processo de de(s)composição/desagregação social iniciado durante a colonização. Por outro lado, há o modo de ver este desenvolvimento apenas como a forma particular que a expansão capitalista adquire na periferia (próprio de um pensamento dualista). É, também, uma maneira de superar o problema do ingresso da modernidade num caminho não clássico, que explica os problemas de nossas revoluções, por meio do desenvolvimento necessário para que ela desse um salto até se nivelar às economias centrais.

A proposta deste trabalho é aprofundar as leituras que abriram o primeiro caminho de análise sobre a regressão da modernidade e o processo de desagregação social que ela originou, ainda hoje crescente no Brasil e América Latina.

Mostrar o eixo histórico que dá unidade à falta de "nexo moral" na formação permite compreender, de maneira mais profunda, o nível de "descomposição" social que se desenvolve até hoje na periferia dentro do contexto do capitalismo contemporâneo.

\section{A formação da fratura brasileira}

O nascimento do Brasil, a partir da colônia, se dá pela conjunção dos "núcleos opostos"; por um lado, um "núcleo orgânico" do sistema colonial de produção, localizado no trabalho dos escravos do litoral e, por outro, sua "periferia inorgânica",

um número mais ou menos avultado de indivíduos desamparados, evidentemente deslocados, para quem não existe o dia de amanhã, sem ocupação formal e fixa, ou desocupados inteiramente, alternando o recurso à caridade com o crime. (PRADO JR., 2000, p. 293).

Esse setor "inorgânico" vive numa situação caótica, tornando-se um mero apêndice da grande exploração, "a estrutura social, a organização política e as formas culturais", todas elas se subordinando à grande exploração (RICUPERO, 2000, p. 140).

Por esta razão, para Caio Prado Jr. (1942) o fundamento da colônia é uma "empresa comercial" destinada a explorar os recursos humanos e naturais necessários para o comércio europeu. É neste sentido que surge a América Latina e, mais especificamente, o Brasil; este é o caráter constitutivo que se manterá ao longo de três séculos e que fará da América Latina o que é hoje. 


\section{ReVistg all paUtg}

\} HISTÓRIA DE UMA FRATURA - BECHER, M. N. \}

O sentido da colônia, desde o começo, não era povoar o território. O "comércio" era o que interessava aos colonizadores, por isso houve esse desprezo pelo povo primitivo da América. A ideia era "ocupar [...] apenas como agentes comerciais, funcionários e militares para a defesa, organizados em simples feitorias destinadas a mercadejar com os nativos e servir de articulação entre as rotas marítimas e os territórios ocupados." (PRADO JR., 2000, p. 12-20).

À medida que se desenvolvem as diferentes atividades de extração dos recursos, começa-se a ver a necessidade de

[...] ampliar estas bases, criar um povoamento capaz de abastecer e manter as feitorias que se fun-dassem e organizar a produção dos gêneros que interessassem ao seu co-mércio. A ideia de povoar surge daí, e só daí. (PRADO JR., 2000, p. 12-20).

Desta maneira, a vida colonial no Brasil sofrerá a falta de um "nexo moral" (PRADO JR., 2000, p. 357), definindo-se pela desagregação, pelas forças dispersas. Estes setores "inorgânicos expulsos" vivem nas áreas pobres e não podem gerar uma organização econômica significativa (DIAS, 1989, p. 386).

É isto, em resumo, que o observador encontrará de essencial na sociedade da colônia: de um lado uma organização está aí no que diz respeito a relações sociais de nível superior; doutro, um Estado, ou antes um processo de desagregação mais o menos adiantado, conforme o caso, resultante ou reflexo do primeiro, e que se alastra progressivamente. (PRADO JR., 2000, p. 356).

De acordo com o livro "Formação do Brasil contemporâneo" (PRADO JR., 1942), no plano das realizações humanas criava-se "algo no$v^{\prime \prime}$, que se concretizava num organismo social complexo e distinto com uma população bem diferenciada étnica e territorialmente, com uma estrutura material particular, constituída com base em elementos próprios, com uma organização social definida por relações específicas e até com certa "atitude" mental coletiva particular. (PRADO JR., 2000, p. 2).

O que define esse "inorgânico", esse antagonismo, esse eixo central para entender o processo de formação do Brasil depois da conquista, nos quais há falta de "nexo moral", visto em seu sentido mais amplo como "o conjunto de forças de aglutinação, complexo de relações humanas mas que mantêm ligados e unidos os indivíduos de uma sociedade e os fundem num todo coeso e compacto" fica inconcluso. Ao contrário, na sociedade colonial, as relações se definem pela "inércia", que apesar de ser "infecunda dá uma certa estabilidade à estrutura colonial.". O que mantém a precária integridade do conjunto são os "laços materiais primários, econômicos e sexuais." (PRADO JR., 2000, p.357). Foi com base nisto que a sociedade se manteve e desta maneira a colônia pôde continuar. 


\section{Revista all paעtg}

\} HISTÓRIA DE UMA FRATURA - BECHER, M. N. \}

Os elementos que dão organicidade são os mesmos que produzem contradições inorgânicas. Para Caio Prado Jr., a organização jurídicopolítica e a estrutura econômico-social do país são um exemplo desta relação: por um lado, configura-se um "Estado Nacional" segundo o modelo do centro capitalista, transplantando para as colônias instituições liberais que garantiam a cidadania; por outro lado, há produção voltada para necessidades estranhas à população local, o que origina "uma maior exclusão para os habitantes." (1957, p. 63).

O Brasil (e a América) foi constituído tanto por aqueles que o povoaram com o fim comercial pelo qual surgiu, quanto pelas massas indígenas que o habitavam antes da conquista, brutalmente arrastadas para o trabalho escravo. Desta forma, iniciou-se a caça do homem pelo homem, as expedições predatórias de gente, em que milhares e milhares de pessoas foram iniciadas na "'beleza' da civilização" (PRADO JR., 1957, p. 23). Também fizeram parte desse regime os escravos trazidos da África, assim como uma parte dos colonizadores que, por alguns períodos e em determinadas regiões, tiveram que se submeter à escravidão.

Segundo Franco realiza-se uma composição da sociedade nacional em que existe um amplo setor formado por "homens livres na ordem escravocrata": em sua maioria pauperizados, relegados a serviços residuais que, em grande parte, não podiam ser realizados por escravos ou não interessavam aos homens com patrimônio. Ocupando o lugar "intermediário" entre a escravidão e os latifundiários, estes homens não podiam nem obedecer à norma em sua totalidade nem desprezá-la, um setor que ficava fora dos setores instituídos pela colônia (FRANCO apud ARANTES, 1992, p. $46,69,73)$.

No período de colonização do Brasil,

a população livre, mas pobre, não encontrava lugar algum naquele sistema que se reduzia ao binômio 'senhor e escravo'. Quem não fosse escravo e não pudesse ser senhor, era um elemento desajustado, que não se podia entrosar normalmente no organismo econômico e social do país. Isto que já vinha dos tempos remotos da colônia, resultava em contingentes relativamente grandes de indivíduos mais ou menos desocupados, de vida incerta e aleatória, e que davam nos casos extremos nestes estados patológicos da vida social: a vadiagem criminosa e a prostituição. Ambos se disseminavam largamente em todas as regiões de certa densidade demográfica. (PRADO JR., 1981, p. 148).

\section{A fratura: acumulação primitiva-empresa comercial}

Prado Jr. é um dos primeiros pensadores marxistas latino-americanos a colocar a ideia da não existência do feudalismo nas colônias da América Latina, afirmando que a conquista foi uma "grande empresa 


\section{ReVistg all pavtg}

\} HISTÓRIA DE UMA FRATURA - BECHER, M. N. \}

colonial" pensada com a finalidade de obter matérias-primas. O "sentido da colônia" é levado "para fora" até o comércio europeu, por uma necessidade do capital de se constituir nos trópicos como fonte de recursos. É a "expansão marítima dos países da Europa", depois do século XV, da qual a conquista da América faz parte, e que levou ao comércio europeu a possibilidade de se desenvolver além do que fora imaginado até o momento por via terrestre. Assim, o que se passou a chamar de "era dos descobrimentos", "não é senão um capítulo da história do comércio europeu." (PRADO JR., 2000, p. 9-20).

Em seu primeiro livro, Evolução política do Brasil, mantendo um diálogo com aqueles que sustentam a tese do "feudalismo" na América Latina, Caio Prado Jr. (1957) assinalava o caráter mercantil da conquista, da qual a explosão marítima foi causa e resultado de uma "burguesia comercial sedenta de lucros, e que não encontrava no reduzido território pátrio satisfação à sua desmedida ambição." (PRADO JR.,1957, p. 11, 91). Assim, a "evolução" do Brasil se caracteriza pelo desenvolvimento da forma capitalista de produção.

Em 1942, com "Formação do Brasil contemporâneo", ele volta a ressaltar o caráter decisivo do século XIX na história do Brasil "apontandoo como o esgotamento do sistema colonial, frente às solicitações ampliadas do capitalismo." (AMARAL FERLINI, 1989, p. 229).

A não existência de "restos feudais" na América marca, para este autor, um ponto de ruptura com a leitura sustentada pelo marxismo até o momento sobre o processo colonial:

Feudal tornou-se assim sinônimo ou equivalente de qualquer forma particularmente extorsiva de exploração de trabalho, o que seria um eixo falso para entender esta forma social constituída a partir da conquista. Tais formas [...] ainda largamente difundidas nas relações de trabalho rural brasileiro, constituem remanescentes, isto sim, do sistema de trabalho vigente legalmente no Brasil até fins do século passado, a saber: a escravidão. (PRADO JR., 1972, p. 32).

Segundo Prado Jr. (2000), o erro mais frequente é confundir escravidão com feudalismo, esquecendo que eles se diferenciam na natureza das relações de trabalho e produção e no papel que cumprem nos processos político-sociais. Ou seja: é impossível pensar estes sistemas fora do modo econômico e social onde se desenrolam. A existência da escravidão não é, desta maneira, o sintoma dos "restos feudais"; é, no entanto, a presença das bases históricas sobre as quais se forjou o capitalismo na América.

A passagem do feudalismo para o capitalismo é um marco que, segundo Prado Jr. (2000), não teve registro nas colônias americanas. Com isso, ele tenta mostrar que a particularidade do capitalismo adquiriu novas formas em sua expansão marítimo-comercial na realidade brasileira. Neste país, não se vive ao estilo europeu, mas segundo formas próprias da periferia. 


\section{Revista all paעtg}

\} HISTÓRIA DE UMA FRATURA - BECHER, M. N. \}

A constituição da colônia, sob essa perspectiva, abriu a possibilidade de outras formulações que pensassem a relação entre o nacional e o internacional como uma linha difusa em relação aos parâmetros dos países colonizadores. Assim, a colônia passou a ser uma entidade que dependia da Europa até na maneira de pensar, convertendo-se em um mero apêndice reprodutor do comércio e das matérias-primas.

Prado Jr. (1957) visualiza a independência do Brasil da mesma maneira, ressaltando que o "desenvolvimento econômico" propicia a "independência política"; isto é, que a "superestrutura política da colônia" não correspondia com "as forças produtivas e a infraestrutura econômica", fazendo-se necessária uma ruptura que permitiria o curso dessa "evolução".

No período de transição entre colônia e nação não existem enfrentamentos violentos, mas no fundo o processo é o mesmo: uma evolução econômica incompatível com o estatuto colonial. Outro efeito pelo qual se levou a cabo a emancipação do Brasil é o de "arranjo político". Deste modo, a independência se realizou por uma simples transferência política de poderes da metrópole ao novo governo brasileiro e, com a falta de participação das massas populares, o poder caiu nas mãos das classes superioras da ex-colônia.

Conquistava-se, então, uma independência em que o povo não teria lugar na nova ordem política. O caráter "classista" que envolve o projeto da independência revelou, por dentro do processo, um viés discriminatório dos direitos políticos. Assim, os grandes proprietários rurais adquiriram todos os direitos políticos que thes permitiam governar sobre aqueles que nunca teriam qualquer possibilidade de eleição nem posse de cargo público, aqueles que não eram considerados "cidadãos ativos" (PRADO JR., 1957, p. 49-55): os trabalhadores e os escravos.

Dando prosseguimento à análise de Prado Jr. (1972, p. 91), observamos que

o capitalismo constituiu historicamente a intensificação em alto grau daquela exploração e opressão, e isso representou um dos importantes fatores de impulsionamento da acumulação capitalista primitiva, isto é, a constituição do capital inicial ou de parcelas importantes desse capital com que se desencadeou, e, em seguida, acelerou o processo de desenvolvimento do sistema produtivo do capitalismo.

Seguindo este pressuposto, o campo brasileiro constituiu-se basicamente por trabalho escravo, pois havia trabalhadores na "qualidade de empregados, de prestação de serviços" sem que fosse um sistema autônomo de produção consolidado (PRADO JR., 1972, p. 92-123).

Deste modo é que a colonização encontra-se unida ao processo de acumulação primitiva, de onde surge o "nascimento sanguinário" da América. Assim, a ocupação do território não se realizou transportando as formas feudais da Europa, mas, como assinala Prado Jr. (2000) foi uma 


\section{ReVistg all pavtg}

\} HISTÓRIA DE UMA FRATURA - BECHER, M. N. \}

"empresa colônia", na qual a monocultura exacerbada e extensiva era financiada por capitais internacionais. Esta leitura se contrapõe às leituras "dualistas" sobre as formações latino-americanas que veem modos feudais na constituição delas.

É em função da "empresa comercial" que o trabalho escravo se inscreve como "comércio de carne humana" (GALEANO, 2008), nascendo como relações sociais capitalistas nas fronteiras europeias durante a formação incipiente do mercado mundial.

A expansão e o desenvolvimento do capital se apoderaram de formas de trabalho e produção típicas de formações sociais pré-modernas, que adquiriram, por meio desta ação, um conteúdo capitalista. Assim, o advento do capital contou com a apropriação dos processos de trabalho tal como foram encontrados, e só posteriormente é que foram introduzidas modificações diversas em sua base material com a intenção de impulsionar a expansão desta nova forma social.

Foi neste sentido, por exemplo, que o capital edificou a máquina no âmbito da "grande indústria", tornando-se possível ultrapassar as "barreiras orgânicas humanas": "não basta que o capital se apodere do processo de trabalho em sua figura historicamente tradicional estabelecida e se limita a prolongar sua duração", "o capital tem que revolucionar as condições técnicas e sociais do processo de trabalho, e portanto o modo de produção mesmo." (MARX, 2004, p. 379-382 \% grifos nossos). Essa tendência foi denominada por Marx (2004) como "subsunção real do trabalho ao capital".

\section{Reação e revolta na fratura}

Segundo Ribeiro (2000, p. 255), o Brasil é implantado como sociedade nacional sobre um imenso território envolvendo milhões de pessoas, cuja contrapartida a esta tarefa unificadora foi a "ordenação da sociedade nacional em cada uma de suas formações, com estreita obediência aos interesses oligárquicos". A própria independência do Brasil é empreendida pela metrópole colonial que desloca a parte mais viva e representativa das classes dirigentes lusitanas e sua burocracia mais competente.

Já o território do Brasil mimetiza-se brasileiro e a independência se organiza tão bem em função de si mesma que continua regendo por mais oitenta anos. Nestas décadas, enfrentam-se e se vencem todos os levantamentos populares, levando seus líderes à morte ou dando-lhes anistia e incorporando-os ao grupo dominante (RIBEIRO, 2000, p. 256).

Após intensas e prolongadas rebeliões, a proclamação da república mobilizou muito pouco as camadas populares, e "uma simples passeata militar foi suficiente para Ihe arrancar [do império] o último suspiro." (PRADO JR., 1957, p. 94). 


\section{Revista all paעtg}

\} HISTÓRIA DE UMA FRATURA - BECHER, M. N. \}

Brasil, esse aglomerado heterogêneo originário de raças e povos díspares: o branco europeu, o negro africano e o indígena foram reunidos pela colonização para produzir "gêneros tropicais demandados pelo mercado europeu", dando o caráter de uma "sociedade nacionalmente organizada" (PRADO JR., 1972, p. 69). O indígena e o negro, trazido da Africa como escravo, foram os que acabaram contribuindo com o esforço físico no desenvolvimento da empresa.

A colonização produziu, com base no monopólio de terra, três classes de população: "o latifundiário, o escravo e o homem 'livre', na verdade dependente. Entre os dois primeiros a relação é clara, são as grandes massas dos terceiros que dão a particularidade." (SCHWARZ, 2008, p. 16).

Nem proprietários, nem proletários, seu acesso à vida social e seus bens dependem materialmente do 'favor', indireto ou direto, de um grande [...] 'é o mecanismo através do qual se reproduz uma das grandes classes da sociedade, envolvendo também outra, a dos que têm [...] O favor é nossa mediação universal [e] o escravismo [acaba desmentindo] as ideias liberais [mas] o favor, tão incompatível com elas quanto o primeiro, as absorve e desloca, originando um padrão particular.' (SCHWARZ, 2008, p. 16-17 - grifo do autor).

Sem a ruptura política das massas com a colônia e com uma continuidade econômico-social baseada no processo da conquista, a América Latina transitou pelo século XIX com a ambiguidade de não poder constituir uma "identidade nacional" que fosse congruente a todo o "aglomerado heterogéneo" sobre o qual se fundou.

Essas massas inorgânicas reagirão, na maioria dos casos, de uma maneira catastrófica, sem objetivos; ao mesmo tempo, serão historicamente massacradas e reprimidas pelo aparato estatal militar, conformado com a finalidade de organizar a produção da colônia.

\section{Aprofundamento da fratura estrutural: desagregação/decomposição}

A compreensão desse eixo central da formação brasileira, ou seja, a falta de um nexo que se vincule às diferentes massas que acabarão povoando os territórios colonizados, tornou-se uma peça-chave para entender os desdobramentos dessa fratura na crise estrutural do capital. O traço da nossa constituição remete a uma fratura, que mostra sua fase mais profunda e sua impossibilidade de unificação quando colocada nos marcos da crise estrutural do capital. Esta fratura, junto à sociedade produtora de mercadorias, universaliza-se e deixa de ser uma característica exclusiva da periferia. 


\section{ReVistg all paUtg}

\} HISTÓRIA DE UMA FRATURA - BECHER, M. N. \}

O capitalismo, a partir dos anos 1970, ingressou em uma nova fase. Neste período, consolidou seu domínio sobre todas as esferas da vida humana e todos os territórios do planeta, unificados numa "sociedade produtora de mercadorias" (MENEGAT, 2012, p. 25).

Impulsionada por grandes transformações produtivas, esta nova fase representa um amadurecimento - e um auge - enquanto sistema. Assim, o "arcaico", entendido como pré-capitalismo ou desenvolvimento insuficiente da produção capitalista, está superado:

o arcaico que vemos agora espalhado pelo mundo, desde os países periféricos até as periferias dos países centrais, é a própria configuração deste modo de produção. O seu progresso não passa de formas ideológicas de um impressionante retrocesso. (MENEGAT, 2012, p.25).

Neste momento, o capitalismo também atravessa uma crise de expansão. As fronteiras internas se fazem por meio das renovações tecnológicas e da inovação de produtos; a externa, pela expansão para novos mercados. Tais limites significam uma "crise estrutural"1 que vai se combinando com os processos de crise conjunturais (Tigres asiáticos e Rússia em 1996-7, México em 1998, Argentina em 2001, bolsa de valores de Nova York em 2001) (MENEGAT, 2012, p.26).

A partir da análise realizada por Schwarz (1993) sobre o livro de Kurz, O colapso da modernização, observa-se que esta débacle sofrida pelas industrializações protegidas do Terceiro Mundo e do socialismo real é vista, sob uma perspectiva mais doutrinária, como a vitória definitiva do mercado e de seus mecanismos.

A partir do ângulo histórico proposto por Kurz,

trata-se da inviabilização de imensos esforços de integração à modernidade, postos fora de combate pelos rigores da concorrência global, ou seja, pela própria lógica do sistema de produção de mercadorias, que passou à autodestruição. (SCHWARZ, 1993, p. 134).

As mudanças, nesta fase do capitalismo, estão marcadas pela Terceira Revolução técnico-científica, que começa a se desenvolver depois da Segunda Guerra Mundial e que atinge o amadurecimento nos anos entre 1970 e 1980. A partir deste processo, suplanta-se o modelo produtivo fordista por novas tecnologias e suas formas de organização. Assim, Menegat (2012, p.27) assinala que

a modificação do modelo fordista da unidade de produção implicou também num rearranjo sócio-político que girou em torno do desmonte

\footnotetext{
${ }^{1}$ Como referência para a análise sobre a crise estrutural do capitalismo, podem ser consultados estes autores, entre outros: KURZ, R. O colapso da modernização. Rio de Janeiro: Paz e Terra. 2003; Os últimos combates. Petrópolis: Vozes. 1997. Com todo vapor ao colapso, Juiz de Fora: UFJF-Pazulin. 2004; MÉSZÁROS, I. Para além do capital. São Paulo: Boitempo. 2002.
} 
do Estado de Bem-Estar social ainda hoje em curso. Estas mudanças liberam energias que não podem ser absorvidas pelo capitalismo, a não ser destrutivamente.

Na medida em que o trabalho é substituído por complexos sistemas de produção automatizados, a "criação de riqueza perde as suas antigas bases materiais", o que provoca um desemprego estrutural gerando uma "imensa crise social", em virtude da perda de sua substância viva: o trabalho (MENEGAT, 2012, p.28).

No ensaio intitulado A atualidade da barbárie, Menegat (2006, p. 41) assinala que

no capitalismo da atualidade da barbárie, marcado pelas ruínas das derrotas das revoluções, a exclusão de milhões de seres humanos dessa esfera do mundo social cria formas de sociabilidade em decomposição, como o desemprego estrutural e a criminalidade, por exemplo, que, definitivamente, não podem ser vistos como uma anomia.

Enfrentado o "limite lógico do capital", os Estados Nacionais passam por um aumento de suas funções repressivas e assistenciais, agregando a elas uma diminuição dos recursos (diferentemente do auge do Estado de Bem-Estar e sua garantia de pleno emprego) e enfrentando grandes corporações, numa situação em que a demanda social está em claro aumento.

Os anos 1990 se caracterizam pela resolução dos impasses produzidos pelas transformações do capitalismo nos países centrais e sua penetração na sociedade brasileira (e latino-americana). O Brasil passou por um forte desmonte do Estado combinado a uma abertura à economia de livre mercado, o que obrigou grande parte da indústria do país a fechar suas portas. É neste quadro que se insere a modernização tecnológica e as novas formas de organização do processo produtivo. Assim, este modo de modernização, de

um crescimento econômico anêmico, foi gerando um exército industrial de reserva gigantesco, que não é mais conjuntural, mas estrutural. Se dá um encontro entre o exército de reserva 'natural' de um país periférico, com as consequências das novas tecnologias produtivas. (MENEGAT, 2012, p. 34).

Arantes (2004) observa que estas massas "excluídas" foram tratadas, através das políticas de "inclusão", sob o foco da fratura social apenas a partir da exclusão. Então, a perspectiva de emancipação se convertia em perspectiva de integração, ao perceber-se que o núcleo dos excluídos representava o setor "moderno" da sociedade que funcionava muito bem, dando as costas à massa de inadaptados: 
O que resta de antagonismo numa sociedade de atores individuais a um tempo fraturada, e, por assim dizer, interacionista, é uma luta por reconhecimento. O discurso sobre a exclusão, a fratura social, oculta detrás dela uma política de produção sistemática de desigualdades. (ARANTES, 2004, p. 51-3).

Para Arantes (2004, p. 290), "a febre ética de hoje é um pobre sucedâneo do empenho político bloqueado." A proposta de integração dos excluídos legitima indiretamente a punição dos atrasados por seu atraso.

Este autor retoma a ideia de Prado Jr., sobre o "nexo moral", para explicar a fratura em que vivem (e que foi se aprofundando) as sociedades contemporâneas, marcando que onde se diz "falta de nexo moral", em uma "quase-sociedade de vanguarda mercantil, podemos ler erosão e invalidação do tal lien social, cuja evaporação contemporânea tira o sono dos franceses ameaçados de brasilianização." (ARANTES, 2004, p. 59).

Em fins de 1960 e princípio de 1970, José Nun (2001, p. 25) elabora a noção de "massa marginal" (que suscitou largo debate com Fernando Henrique Cardoso). Com isto, tinha a intenção de enfrentar o "hiperfuncionalismo da esquerda", que se empenhava em demonstrar que mesmo o último dos camponeses sem terra ou dos vendedores ambulantes era não apenas funcional, mas também decisivo para a acumulação do capital.

Com a incorporação desta noção, não substituía, mas complementava a de "exército industrial de reserva". Pretendia-se mostrar que a "massa marginal" exigiria políticas para esse excedente, e que isto significaria estratégias de a-funcionalização da não funcionalidade da superpopulação relativa, favorecendo distintos graus de autonomia dos subsistemas que a contêm. São ilustrações disso as situações aparentemente tão dissimilares quanto a persistência do gamonalismo na serra peruana e o minifúndio no México. (NUN, 2001, p. 139, 242-243).

Baseado na leitura dos Grundrisse, Nun (2001, p. 42) resgata que, para Marx, "o excedente de população é sempre relativo, mas não aos meios de subsistência em geral senão ao modo vigente para sua produção." Esse é o núcleo da crítica de Marx à concepção abstrata e a-histórica de Malthus. Nas palavras de Marx, que Nun extrai dos Grundrisse, "é então unicamente um excedente para tal nível de desenvolvimento." (MARX apud NUN, 2001, p. 42).

Ainda para Nun (2001, p. 106) uma parte cada vez maior da superpopulação relativa se transforma em uma "massa marginal". A falta de funcionalidade dessa massa não é uma consequência buscada pelo comportamento dos agentes econômicos, mas o efeito dessa "contradição fundamental" entre as relações de produção imperantes e o nível de desenvolvimento alcançado pelas forças produtivas.

Para superar o dilema da exclusão é preciso compreender que "O mercado é uma formação social que não admite nenhum 'exterior'" (ARANTES, 2004, p. 52), que o desempregado não encontra mais quem lhe compre 


\section{Revista all paעtg}

\} HISTÓRIA DE UMA FRATURA - BECHER, M. N. \}

a força de trabalho, que o pobre é um consumidor insustentável e que os descartados são "descartados porque estão absolutamente incluídos." (ARANTES, 2004, p. 295). É o que Kurz (1993, p. 195) chama de "sujeitos monetários sem dinheiro."

Configura-se, assim, um vasto espaço no qual "vivem os caídos transitando sua desumanização." Deste modo, o que os sustinha até o momento, como sujeitos, "desvaneceu, a ordem simbólica vigente cai e arrasta em sua queda a condição de sujeito. A miséria tem efeitos sobre os vínculos, os corpos, a capacidade de simbolizar, o universo de valores, desliga a composição subjetiva e aniquila a humanidade prévia." (FERRARA, 2003, p. 24).

Uma parte da esquerda, ultrafuncionalista, desconheceu ou negou a existência dessas massas inorgânicas, excluídas, marginais, que sobravam, ocultando o debate sobre o lugar que elas guardam nos processos de lutas sociais. Arantes (2004) mostra que, ante à impossibilidade de incorporação, passa-se à proposta de uma integração por reconhecimento, identitária e solidária. É a ideia de reconstruir pontes entre o incluído e o excluído, onde o reconhecimento dessa dualidade não leve a uma crítica da produção sistemática da desigualdade.

Neste contexto, o comportamento da burguesia se vê refletido em "um descompromisso autoritário" com as necessidades coletivas das sociedades nacionais de onde surgiram.

O privilégio dado ao interesse financeiro, levando-a a sustentar estupidamente as conseqüências antissociais destas suas ações; a sua frieza social amesquinhadora que a torna abertamente cruel, realizando como algo natural e inevitável a contenção da pobreza por meio da criminalização dos pobres, cujo resultado é o genocídio das 'massas sobrantes'. (MENEGAT, 2012, p.?).

Este grupo acaba personificando as necessidades do capital.

Por outro lado, o proletariado sofreu, nas últimas décadas, as consequências deste processo de desmoronamento, vendo-se afetado pelo desemprego estrutural que debilitou fortemente suas lutas. Isto fez aumentar o exército industrial de reserva, que permite às empresas derrotarem qualquer ação coletiva dos trabalhadores. Somado a isto, há a exigência de uma formação técnica do trabalhador, que aumenta a competição cruel entre a maior parte da população que busca sobreviver em meio à crise.

Além do desemprego estrutural, os trabalhadores assalariados sofrem as consequências da chamada "flexibilização trabalhista", que transformou os empregos estáveis em totalmente instáveis, "terceirizando-os", ou seja, entregando diferentes setores da produção a várias empresas que levem a cabo o processo. Assim, já não existe uma única unidade de produção, o que leva ao desaparecimento de um "território" em comum para a organização coletiva: a fábrica. Esta, como lugar de luta, de organização e de estratégia, desaparece, desmembrando o coletivo em uma individua- 


\section{ReVistg all paUtg}

\} HISTÓRIA DE UMA FRATURA - BECHER, M. N. \}

lidade abstrata, na qual se perde a referência de com quem e para quem se trabalha.

Um terceiro elemento é a alienação do trabalho, que surge em consequência a um aprofundamento cada vez maior da divisão técnica, tornando impossível que cada trabalhador compreenda o que realmente se faz em cada uma das funções.

Segundo Schwarz (1993, p. 136), se com Marx assistimos ao aprofundamento da luta de classes, em que as sucessivas derrotas do jovem proletariado são outros tantos anúncios de seu ressurgimento mais consciente, com o aprofundamento da crise estrutural, 150 anos depois,

o antagonismo de classes perdeu a virtualidade da solução, e com ela a substância heróica. A dinâmica e a unidade são ditadas pela mercadoria fetichizada - o anti-herói absoluto - cujo processo infernal escapa ao entendimento de burguesia e proletariado, que enquanto tais não o enfrentam.

Com estes elementos colocados como consequência do quadro de crise estrutural, hoje, torna-se difícil pensar na organização coletiva do proletariado, dadas as condições mencionadas. Como Menegat (2012) aponta, não podemos saber se são parte de uma situação conjuntural, que transita de um período de conquistas materiais dentro da ordem burguesa para um de derrotas e ajustes, ou se estamos frente a uma situação estrutural. Esta se determina pela incorporação dessa classe ao sistema, depois de haver sido devidamente domesticada e aburguesada durante anos por hábitos de consumo, sem os quais já não consegue pensar-se. Há, ainda, uma visão de política de Estado em que a ideia de outra forma de vida social perde seu lugar.

A este quadro soma-se a "globalização do mercado" com a intensificação e flexibilização da acumulação do capital, que vai acelerando e aprofundando a transferência de riquezas dos países periféricos para os centrais, e das classes subalternas para os ricos, dentro de um mesmo país. Completa-se, assim, "o quadro de uma imensa cratera que se abre feito ferida nas sociedades do 'elo mais fraco'." (MENEGAT, 2006, p. 92).

O Estado, neste contexto, configura-se ao mesmo momento como repressivo e assistencialista. Enquanto realiza uma administração coercitiva da crise, a ela reforça com um assistencialismo que se disfarça de "novos direitos". Assim, este "poder estatal" consegue, por meio do ato de "inclusão coercitiva" das massas que sobram, construir um amplo campo de criminalização da pobreza. A partir deste lugar, as massas empobrecidas serão as responsáveis pela falta de "nexo" social, que será aprofundado com a proliferação das políticas de Tolerância Zero (Brasil), Unidades de Polícia Pacificadora (Rio de Janeiro), Policía Metropolitana (Buenos Aires), Comando de Acción Preventiva (Córdoba-Argentina), entre tantos outros. (BRITO, 2010). 


\section{Revista all paעtg}

\} HISTÓRIA DE UMA FRATURA - BECHER, M. N. \}

García Linera (2004, p. 38) mostra como, entre os anos de 2001 e 2004 (até agora, ano das principais revoltas na Bolívia), em diversas capitais provinciais da Bolívia se criaram "polícias comunitárias" que resguardavam a ordem pública em nome da Federación Campesina.

Para Menegat (2006, p. 99), para que esse "arranjo social" possa prosseguir sem "ferir o processo excessivo de produção", em um regime de apropriação privada de riqueza, "é necessário hipertrofiar as funções policiais do Estado". Essa operação não se restringe ao simples "aumento dos contingentes repressivos, mas, numa manobra bastante sutil, incorpora à função repressiva as maiorias eleitorais e a chamada opinião pública."

Segundo Oliveira (2003, p. 70), os Estados Nacionais na América Latina se converteram em "Estados de exceção" num duplo sentido: "existem para proteger os interesses dos capitais financeiros e mantêm o grosso de suas populações em estado de indigência, de excepcionalidade, numa funcionalização da pobreza que é a pior das exceções." Converteram-se em "administradores das políticas de funcionalização da pobreza", de onde surgem as "bolsa-escola", "bolsa-alimentação", "primeiro emprego", "começar de novo", "fome zero", "jefe y jefa de hogar" etc.

A violência cotidiana fala da profundidade da crise de legitimação do Estado, que acaba se resolvendo a favor das tendências totalitárias, já muito bem conhecidas na região, recuperando e atualizando velhos modelos ditatoriais com violência.

A "naturalização da barbárie" se efetivou consensualmente de tal maneira que alguns chamam ingenuamente de "pensamento único", sem atentar para "o fato de que se trata efetivamente da naturalização que sempre esteve em curso no mundo burguês, fundada por este axioma do pensamento moderno que é a 'natureza humana'." (MENEGAT, 2006, p. 100).

Schwarz (1993), continuando no caminho de Kurz (1992), observa que estas nações que haviam se lançado à industrialização tardia perdem as condições de coesão e se convertem em "sociedades pós-catástrofe", nas quais o projeto de modernização que, supostamente, iria atender às demandas de maneira universal se perdeu no passado. "Para estes países, a reprodução coerente no espaço da concorrência global deixou de ser um horizonte efetivo, e predomina a tendência à desagregação. Noutras palavras, a generalização do salário e da cidadania está mais distante." (SCHWARZ, 1993, p. 136).

Desta maneira, Schwarz (1993) assinala que o desenvolvimentismo liberou e arrancou as populações do velho enquadramento para reenquadrá-las em um esforço de industrialização nacional, abandonandoas sem que tivessem para onde voltar, na qualidade de "sujeitos monetários sem dinheiro" ou de ex-proletários virtuais, agora disponíveis para a criminalidade e os fanatismos nacionalistas ou religiosos (KURZ, 1992, p.195). 


\section{heVistg all paUtg}

\} HISTÓRIA DE UMA FRATURA - BECHER, M. N. \}

A partir dos anos 1990, abre-se, na América Latina e no Brasil, um processo de regressão e revolta social que apresenta novas características. Estas lutas não são apenas manifestação de um processo de "barbárie", mas também apresentam, para a esquerda, experiências coletivas de organização que abrem a possibilidade de colocar novos elementos em debate. Essas manifestações representam um desafio ante a um panorama de catástrofe. 


\section{Revistg all paUtg}

\section{Referências}

ARANTES, P. E. Sentimento da dialética. São Paulo: Paz e Terra. 1992. . Zero à esquerda. São Paulo: Conrad. 2004.

BRITO, F.M.S. Acumulação (democrática) de escombros. Tese (Doutorado) - Escola de Serviço Social/UFRJ. Rio de Janeiro. 2010.

FERLINI, V.L.A. A fidelidade à história. In: D'INCÃO, M. A. (Org.). História e ideal: ensaios sobre Caio Prado Júnior. São Paulo: Brasiliense; Unesp. 1989. FERRARA, F. Más allá del corte de rutas. Buenos Aires: La Rosa Blindada. 2003. GALEANO, E. Las venas abiertas de América Latina. Madrid: Siglo XXI. 2008. GARCÍA LINERA, A. La crisis del Estado y las sublevaciones indígenoplebeyas. Bolivia: Muela del Diablo. 2004.

KURZ, R. O colapso da modernização. São Paulo: Paz e Terra. 1992.

DIAS, M.O.L.S. Impasses do inorgânico. In: D'INCAO, M.A. (Org.). História e ideal: ensaios sobre Caio Prado Júnior. São Paulo: Brasiliense/Unesp. 1989. MARX, K. El capital. Buenos Aires: Siglo XXI. 2004.

MENEGAT, M. O olho da barbárie. São Paulo: Expressão Popular. 2006. . Estudo sobre ruínas. Rio de Janeiro: Revan. 2012.

NUN, J. Marginalidad y exclusión social. Buenos Aires: Fondo de Cultura Económica. 2001.

OLIVEIRA, F de. Crítica à razão dualista: o ornitorrinco. São Paulo: Boitempo. 2003.

PRADO JR., C. Evolução política do Brasil (1933). São Paulo: Brasiliense. 1957. . A revolução brasileira (1966). São Paulo: Brasiliense. 1972. . História econômica do Brasil (1943). São Paulo: Brasiliense. 1981. . Formação do Brasil contemporâneo (1942). São Paulo: Folha de São Paulo. 2000.

RIBEIRO, D. O povo brasileiro. São Paulo: Companhia das Letras. 2000. RICUPERO, B. Caio Prado Jr. e a nacionalização do marxismo no Brasil. São Paulo: 34/Fapesp. 2000.

SCHWARZ, R. Ainda o livro de Kurz. Revista Novos Estudos Cebrap, São Paulo, n.37, p. 133-137, nov. 1993. . Ao vencedor as batatas. São Paulo: Duas Cidades/Editora 34. 2008.

Recebido em 20 de agosto de 2014 Aprovado para publicação em 25 de novembro de 2014. 